\title{
Incorporating interactive teaching approaches in the tertiary science classroom; Benefits, challenges and deterrents to use in a Jamaican university
}

\author{
Cliff Kelvin Riley ${ }^{1,3}$, Beverley Dawn Myers ${ }^{2,3}$ \\ ${ }^{1}$ College of Health Sciences, University of Technology, Kingston, Jamaica \\ ${ }^{2}$ Faculty of Science and Sport, University of Technology, Kingston, Jamaica \\ ${ }^{3}$ Faculty of Humanities and Education, University of the West Indies (Mona campus) Kingston, Jamaica
}

Email address:

criley@utech.edu.jm (C. K. Riley)

\section{To cite this article:}

Cliff Kelvin Riley, Beverley Dawn Myers. Incorporating Interactive Teaching Approaches in the Tertiary Science Classroom; Benefits, Challenges and Deterrents to Use in a Jamaican University. Science Journal of Education. Vol. 2, No. 5, 2014, pp. 146-151.

doi: $10.11648 /$ j.sjedu.20140205.12

\begin{abstract}
The extent to which lecturers utilise interactive teaching strategies in the tertiary science classrooms at a tertiary institution in Jamaica was investigated. Interactive strategies used, preferred strategy, frequency of use, perceived benefits to students, deterrents to use, and challenges faced with implementation were investigated. The sample comprised of 60 full-time science lecturers with a minimum undergraduate teaching load of 10 contact hours per week. The population comprised primarily of females $(93.3 \%)$ with a mean age of $38.1 \pm 3.67$ years. The results show that teacher-led discussion (90\%) and cooperative learning strategies $(50 \%)$ were the most frequently used interactive teaching approaches employed by the lecturers while peer teaching was the least (8\%). Further analysis of lecturers' views of their teaching approach revealed that all lecturers facilitated in-class discussions, student-teacher interactions and questions from students at some point during their lectures. Preparation time $(40 \%)$, increased workload $(40 \%)$ and poor student participation $(40 \%)$ were identified as the primary challenges faced while time restriction $(90 \%)$ was the main deterrent to using interactive strategies by lecturers in the classroom. Despite this however, lecturers reported that interactive teaching strategies were explored and incorporated during their lectures in a bid to improve student comprehension, improve the learning environment, and build critical and lateral thinking skills. The results also suggest that curriculum scope and institutional policies did not impact negatively on the lecturers' ability to incorporate interactive teaching strategies in their classroom.
\end{abstract}

Keywords: Interactive Teaching, Tertiary Science Classroom, Jamaican University, Benefits of Interactive Teaching

\section{Introduction}

"Our lecturer cannot teach..." is a common thought which resonates in the minds of many undergraduate students when they sit in a classroom with a lecturer/instructor who is an expert in his or her discipline, but lacks experience or skills to engage students in the learning process. According to Djajalaksana [1], this scenario is more common in higher education institutions as many lecturers at the master and doctoral levels did not undergo any formal instructional skills training. Lubienski [2] further highlighted the fact that teaching in the $21^{\text {st }}$ century should not be static or deeply grounded in the traditional expository delivery modality. Instead, it should involve the implementation of teaching approaches that are likely to result in the facilitator/lecturer achieving the desired teaching and learning outcomes. Interactive teaching is one such educational innovation which has impacted positively on teaching and learning at all levels. Interactive teaching approaches should create stimulating environments where students are motivated to learn and are given the freedom to explore, discover and enquire [3].

The National Literacy Strategy, England characterised teaching as interactive when students' contributions are encouraged, expected and extended to others [4]. As such, in interactive classes, students' participation should be at a higher level of autonomy than that commonly found in the traditional initiation-response-feedback approach. Despite this however, several studies have shown that the dominant teaching strategy utilised in adult education involves teacher talk and persistent use of the initiation-response-feedback as 
the principal form of teaching [5-7]. Additionally, little emphasis is placed on student responses, and sustained student-student and student-teacher interactions at the tertiary level [6].

Interactive teaching strategies have reaped success at all levels of education; however, at the tertiary level it has been shown to significantly improve attendance, student engagement in active learning and achieving learning outcomes [2]. It is believed that students clarify their ideas by writing or talking about them. Additionally, research showed that emphasizing interactions during lessons helps in shifting the classroom from an environment in which students are totally dependent on the teacher to one in which students assume more responsibility for validating their own thinking $[2,8]$. According to Conway [9], the relationship developed by a lecturer and his/her class depends in part on the learning environment they create. This environment is greatly influenced by the level of interaction between students and lecturer, attitude towards student learning, knowledge of the material, preparedness and the proficiency in which each component of the lecture is delivered. Additionally, adult learners tend to respond best in an environment in which they can develop a sense of belonging and therefore feel comfortable making a contribution. In such an environment, students become better able to exchange their ideas, reveal their lack of understanding (or alternate conceptions), and put forward suggestions without feeling embarrassed or humiliated [9]. Such an environment is greatly facilitated and often created during interactive teaching.

The opportunity for using interactive teaching and learning strategies varies considerably, and depends on the size and purpose of the class along with the nature of the students. Interactive strategies such as teacher led questioning and guided discussions are usually effective in all classes. Case studies and cooperative learning approaches on the other hand are usually more effective in smaller groups [10]. Additionally, the degree to which these approaches succeed depends heavily on the atmosphere which the lecturer creates. As such, the lecturer's attitude towards student learning and level of preparation impacts significantly on the success of a lesson. A lecturer's ability to stay alert to the state of the class can make the difference between merely giving an address and achieving genuine communication and learning. With this in mind, the study was designed to investigate the extent to which interactive teaching strategies are employed by tertiary science lecturers at a major tertiary institution in Jamaica. Emphasis was placed on the types of teaching strategies used, perceived benefits to students, deterrents to their use and limitations in implementing the strategies in the tertiary science classroom.

\section{Methodology}

\subsection{Study Design}

A quantitative non-experimental survey design was used to collect and statistically test data to answer the research questions. A 34 point researcher-made instrument was used to investigate the extent to which interactive teaching strategies were incorporated by fulltime science lecturers employed to a prominent university in Jamaica. To this end, the following six research questions were formulated to guide the study; a. To what extent are interactive teaching strategies used by science lecturers in the institution? b. What is/are the most commonly used interactive teaching approaches used by lecturers employed to the university? c. What are the primary limitations and deterrents faced by lecturers while attempting to incorporate interactive teaching strategies in their lectures? d. What factors contribute to a lecturer's decision to use an interactive teaching strategy? e. What are the perceived benefits of an interactive classroom to students?

\subsection{Sample Population}

At the time of data collection, a total of 100 lecturers were employed to the two Faculties in which the study was undertaken. Eighty (80) were employed on a full time basis and 20 on part-time or prorated basis. Only full time lecturers, teaching at least one science related module and carrying a minimum of 10 contact hours per week were included in the study. Part-time lecturers, prorated lecturers, full-time lecturers with less than 10 contact hours per week, lecturers not teaching science related modules or teaching related modules using an online platform only were excluded. Sixty (60) full-time lecturers representing $75 \%$ of the eligible population were selected randomly using a random number table. The population comprised primarily of females (56) with $10 \%$ of the population having Bachelor's degrees (pursuing Masters or Doctorial studies), $30 \%$ having Master Degrees, $40 \%$ having PhD's and $20 \%$ other terminal professional degrees.

Full-time academic staff members are mandated by the institution to incorporate innovative teaching strategies and develop approaches to actively engage students in the learning and teaching processes. Additionally, full-time lecturers are allotted up to 20 hours per week (of the total 40 hour work week) to prepare their teaching material and explore approaches to improve their teaching. Part-time lecturers and administrators with reduced teaching load are not privy to such allocations and as such may not choose to incorporate innovative teaching approaches such as teacher led questioning and answers, structured discussions, case studies, cooperative learning and/or other interactive strategies.

\subsection{Data Collection}

A 34 point researcher-made, closed ended, self administered questionnaire was used for data collection after pilot testing. After pilot testing and analysis of internal consistency, a Cronbach alpha of 0.833 was obtained indicating that the instrument was reliable (Cronbach for individual items ranged from 0.796-0.845). The instrument was designed to test the research questions with each item carefully incorporated based on evidence of effectiveness and 
reliability from the literature. Items in Section II on teaching practice and approach was an amalgam of findings from Trigwell et al. [11] and Deslauriers et al. [3]. Section III items were adopted from Djajalaksana [1] and Section IV adopted from Kuh [12] and Smith [13]. Section I consisted of 2 questions aimed at collecting demographic data while Section II comprised of 14 questions (1 limited response and 13 Likert scale questions) aimed at determining the teaching approach used and lecturers' views of the strategies incorporated in their science classroom. Section III consisted of 15 questions (4 limited response and 11 likert scale type questions) aimed at identifying the interactive teaching strategies commonly implemented by lecturers and reasons for using the strategies. Section IV consisted of three limited response questions aimed at identifying common deterrents and limitations to using interactive teaching strategies among the sample.

\subsection{Ethical Considerations}

Ethical approval was sought from and granted by the Ethics Committee of the tertiary institution. All participants gave written informed consent before participating in the study. Each participant was assigned a unique code designed to protect their privacy and confidentiality.

\subsection{Statistical Analyses}

Test for validity, reliability, significance and other statistical analysis were done using Statistical Package for Social Sciences version 20 (SPSS 20). Statistical significance was obtained at $95 \%$ confidence limit. Reliability and internal consistency of the instrument were ascertained from a Cronbach alpha analysis after pilot testing. Cronbach alpha value $>0.75$ was considered acceptable [14]. Tabulated data were represented as Mean \pm Standard deviation.

\section{Results}

\subsection{Teaching Practice and Approach}

Analysis of lecturers' views of their teaching approach indicated that all the participants facilitated in-class discussions, student-teacher interactions and questions from students (mean scores of $4.733 \pm 0.45,4.93 \pm 0.25$ and $4.87 \pm$ 0.34 respectively). However, lecturers scored poorly in providing timely feedback $(3.9 \pm 0.76)$, allowing students to evaluate their own work $(3.87 \pm 0.68)$ and allowing students to set their own learning objectives $(3.27 \pm 1.14)$. Table 1 below outlines the mean score for each item.

Table 1. Mean score of lecturer's views on their teaching approach.

\begin{tabular}{llll}
\hline Question: In my class, I: & Mean score \pm St. Dev & \% that facilitate activity & 100.00 \\
\hline 4. & Facilitate discussions & $4.73 \pm 0.45$ & 93.40 \\
5. & Facilitate peer teaching & $4.20 \pm 0.55$ & 93.40 \\
6. & Facilitate cooperative learning & $4.23 \pm 0.63$ & 90.00 \\
7. & Facilitate student-student interaction & $4.50 \pm 0.51$ & 100.00 \\
8. & Facilitate student-teacher interaction & $4.93 \pm 0.25$ & 83.33 \\
9. & Provide timely feedback & $3.90 \pm 0.76$ & 96.67 \\
10. & Identify and address misconceptions & $4.37 \pm 0.56$ & 86.67 \\
11. & Articulate to students what is expected of them & $4.40 \pm 0.72$ & 83.33 \\
12. & Allow students to evaluate their own work & $3.87 \pm 0.68$ & 93.33 \\
13. & Allow students to give constructive feedback to their peers & $4.23 \pm 0.57$ & 40.00 \\
14. & Allow students to set their own learning objectives & $3.27 \pm 1.14$ & 86.67 \\
15. & Use teacher feedback to improve students' work & $4.47 \pm 0.51$ & 100.00 \\
16. & Facilitate questions from students & $4.87 \pm 0.34$ & \\
\hline
\end{tabular}

Values in table above represent Mean Scores \pm Standard Deviation $(n=60)$.

Mean scores $>4.0$ are considered strong while values $<4$ are considered weak

\subsection{Use of Interactive Teaching Strategies}

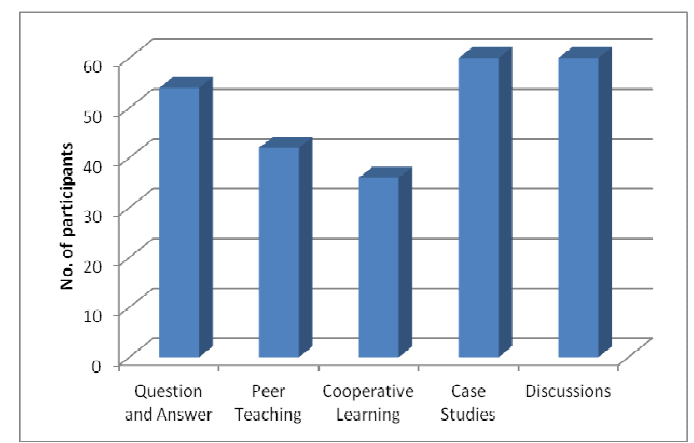

Figure 1. Teaching strategies used by the tertiary science lecturers in Science modules.

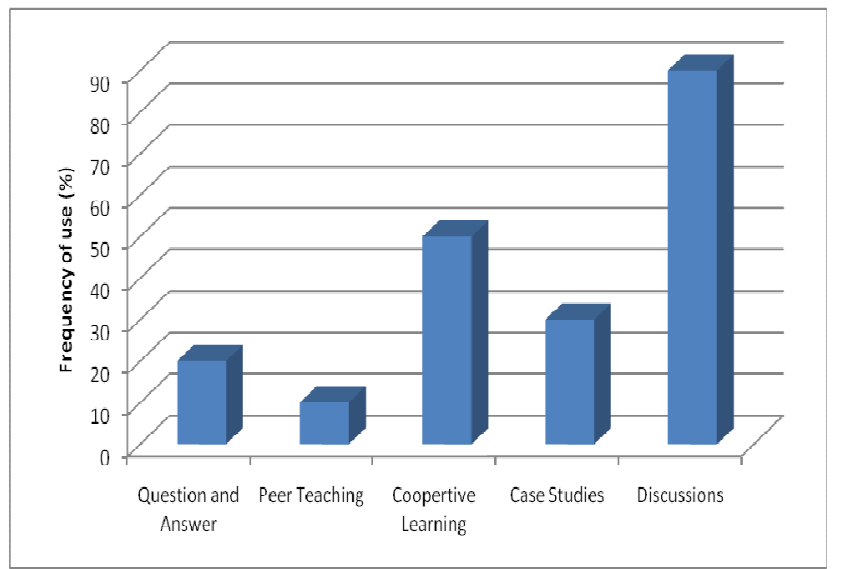

Figure 2. Frequency of use of interactive teaching strategies in tertiary science classroom by lecturers. 
All 60 participants reported use of one or more interactive teaching strategies in their science classrooms. Fifty percent $(50 \%)$ of the participants reported that interactive strategies were used most of the times, $30 \%$ always and $20 \%$ sometimes. All the participants reported that discussions and case studies were used at some point during their lectures. However, only $36(60 \%)$ reported to have ever used Cooperative learning strategies in the classroom (Fig, 1).

Additionally, $90 \%$ of the participants indicated that discussion was the most frequently used strategy while peer teaching was the least (Fig. 2).

The results also show that all the participants incorporated interactive teaching strategies in their science classroom to improve student comprehension, build critical and lateral thinking skills, to provide a positive working environment and improve overall academic performance (mean scores of $4.80 \pm$ $0.41,4.60 \pm 0.67,4.57 \pm 0.63$ and $4.50 \pm 0.51$ respectively). The majority of lecturers did not incorporate interactive strategies to improve classroom control or to meet requirements of the curriculum $(3.53 \pm 1.25$ and $2.73 \pm 1.26$ respectively). Table 2 outlines the mean scores for lecturers' reasons for incorporating interactive teaching strategies in their science classroom and the percentage of participants who selected the item as a reason for incorporating different interactive teaching strategies.

Table 2. Mean scores and number of participants who use interatctive strategies to achieve desired outcome.

\begin{tabular}{llll}
\hline Reasons why lecturers use Interactive strategies & Mean score \pm St. Dev & (\%) Agreeing \\
\hline 21. & Improve student comprehension & $4.82 \pm 0.41$ & 100.00 \\
22. & Increase student interest & $4.33 \pm 0.80$ & 80.00 \\
23. & Improve overall academic performance & $4.50 \pm 0.51$ & 100.00 \\
24. & Allow students to apply theory to practice & $4.40 \pm 0.81$ & 80.00 \\
25. & Develop meaning to content & $4.33 \pm 0.88$ & 73.33 \\
26. & Develop my teaching skills & $4.12 \pm 0.75$ & 80.00 \\
27. & Meet the requirements of the curriculum & $2.73 \pm 1.26$ & 30.00 \\
28. & Control the classroom & $3.53 \pm 1.25$ & \\
29. & Promote cooperative learning & $4.33 \pm 0.76$ & \\
30. & Build critical and lateral thinking skills & $4.60 \pm 0.67$ & \\
31. & Provide a positive learning environment & $4.57 \pm 0.63$ & 100.00 \\
\hline
\end{tabular}

Values in table above represent Mean \pm Standard Deviation $(\mathrm{n}=30)$.

Mean scores $>4.0$ are considered strong while values $<4$ are considered weak

\subsection{Challenges Faced and Deterrents to Using Interactive Strategies}

Eighty percent $(80 \%)$ of the lecturers indicated that the greatest challenge faced with incorporating interactive teaching strategies was time restrictions. Additionally, 70\% indicated that preparation time was also a significant factor. Interestingly, only $40 \%$ reported student participation, increased workload and access to resources having a negative impact on their ability to implement interactive strategies in their classroom. None of the participants reported the scope of the curriculum as posing a challenge (Fig. 3).

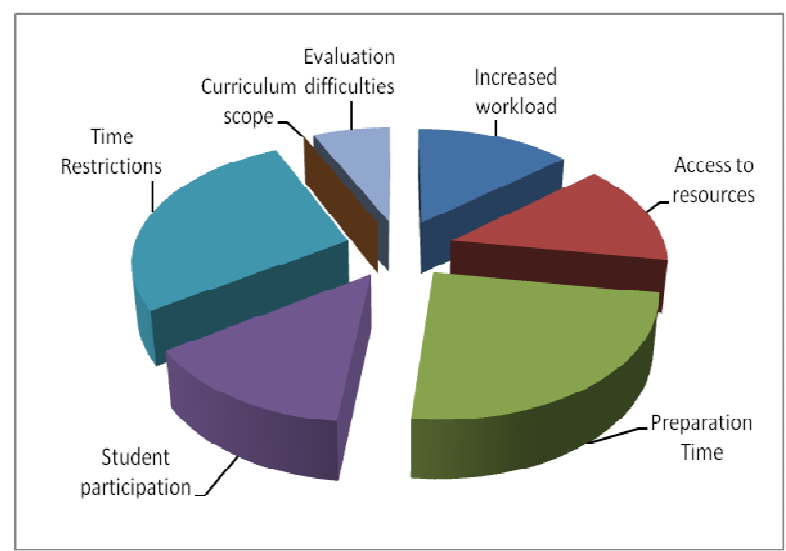

Figure 3. Challenges faced by lecturers in incorporating interactive teaching strategies in the tertiary science classroom.
Further to this, $90 \%$ of the participants reported time restriction as the biggest deterrent to using interactive teaching strategies in the classroom. Only $20 \%$ reported curriculum restrictions, classroom management and alienation of timid students as deterrents. Just over $6 \%$ of participants reported the lack/absence of institutional policy guidelines as a deterrent (Fig. 4).

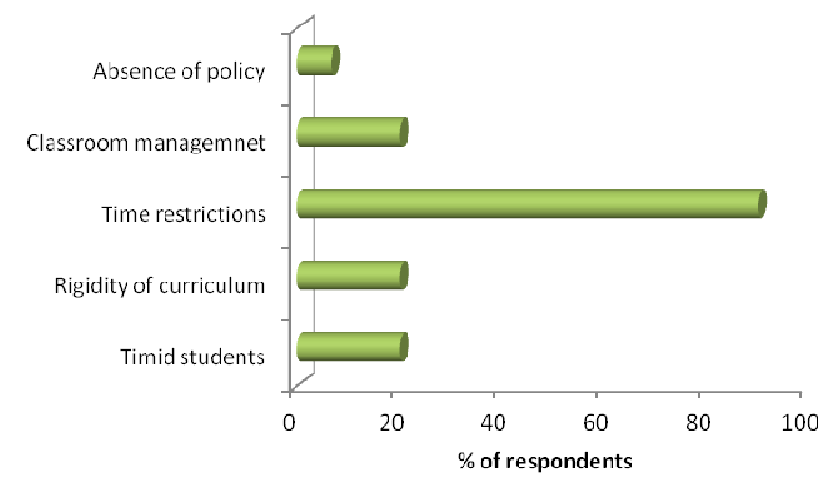

Figure 4. Deterrents to using interactive teaching strategies in the tertiary science classroom.

Student learning capability and curriculum objectives were identified as the primary contributing factors in lecturers deciding to use interactive teaching approaches $(70 \%$ and $60 \%$ respectively). Fifty percent $(50 \%)$ of the participants indicated that classroom size also played a key role in deciding on which strategy to use (Fig.5). 


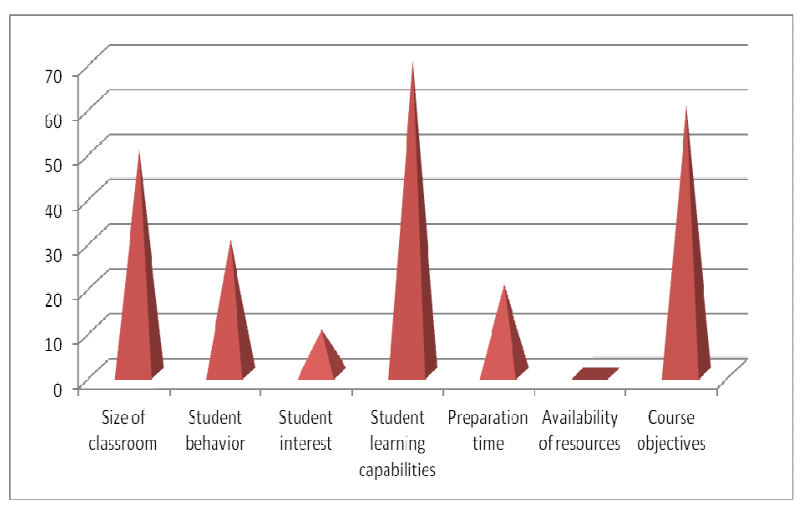

Figure 5. Factors guiding lecturers choice of interactive strategy used in their tertiary science classroom.

\section{Discussion}

Research has shown that the incorporation of interactive teaching strategies such as interactive lectures, case studies, discussions, peer teaching/cooperative learning and questions and answers significantly improved students' understanding of fundamental science concepts and understanding at the tertiary level [15]. The results obtained indicate that the primary teaching method used by the university lecturers was lecturing. Despite this however, the traditional verbatim lecturing method was not dominant as all participants in the study reported the use of one or more interactive teaching strategies during their science lectures. All the participants incorporated discussions and case studies, while $83.8 \%$ utilised questions and answers, $70 \%$ peer teaching and $60 \%$ cooperative learning.

Additionally, $90 \%$ of the participants reported discussions as the primary and most frequently used interactive strategy in their classroom. This therefore suggests that interactive teaching strategies are widely utilised and incorporated into tertiary science lectures at the institution studied. This further implies that tertiary science lecturers in the sample population created opportunities for students to explore ideas, develop critical thinking skills, discuss societal issues and problems, and engage in group decision making and problem solving, all of which are achieved through discussions [10]. Lubienski [2] highlighted the fact that placing emphasis on interactions during lessons helps in shifting the classroom from an environment in which students are totally dependent on the teacher to one in which students assume more responsibility for validating their own thinking. Furthermore, Larson [16] highlighted the fact that interactive lectures create opportunities for students to share ideas with their peers and teacher, speak freely, build communication skills, improve the learning environment and their academic performance. A large majority of lecturers $(70 \%)$ reported that their choice of the interactive strategy was guided by the students' learning capacity, $60 \%$ were guided by the curriculum objectives and assessment guidelines while 50\% were guided by the class size. Discussions and question and answer were primarily used for large groups, while case studies and cooperative learning approaches were reportedly used with smaller classes. The findings were in agreement with the recommendations put forward by Steinert \& Snell [17].

All the participants reported the use of interactive strategies as an aide in improving student comprehension, building critical and lateral thinking skills, creating a positive working environment and improving overall academic performance. The strategies were not used to control or improve classroom management or to meet the requirements of the curriculum. Additionally, the participants were of the view that their teaching strategies did not allow for students to set their own learning objectives. This is believed to be directly linked to the requirements of the profession as set out by their pre-determined/established competences. Interestingly, however, Weimer [15] highlighted the benefits of allowing students to evaluate their own learning and setting their leaning objectives. Additionally, Wilen [10] is of the view that effective use of discussions can impact positively on classroom management, especially for large groups. For teaching to be effective, it must involve a process of facilitating learning rather than simply transmitting knowledge from the teacher to the learner [18]. As such, opportunities must be created to facilitate student-student and student-teacher interactions, self evaluation and inclusion of personal learning goals. Furthermore, adult learners should be allowed the opportunity to evaluate their own learning, concepts and ideas [10].

Despite the wide scale non-mandatory incorporation of interactive teaching strategies into the science classroom by tertiary lecturers, it must be noted that several challenges and deterrents were also reported. Owing to the lack of institutional policy guidelines on mandatory the use of interactive teaching approaches some lecturers view the use of these approaches as added work. Time restriction and preparation time were listed as the biggest deterrents for lectures in incorporating and/or expanding the use of interactive teaching strategies in their science classroom. Interestingly, however, only $40 \%$ of the participants reported increased workload, student participation and access to resources as challenges. According to Gambrell [18] interactive teaching strategies such as discussions, question and answers, case studies and cooperative learning in the science classroom can pose some challenges, the most common being; possibility that students will not participate, activities being dominated by some students, preparation may be time consuming and loss of effectiveness as class size increases. Similar challenges and deterrents were also reported by Wehrli \& Nyquist [19].

\section{Conclusion}

The study indicates that science lecturers at the institution studied incorporated one or more interactive teaching strategy in their tertiary science classroom in a bid to improve student comprehension, improve the learning environment and build critical and lateral thinking skills. The lack of clear policy guidelines impacted on the wide scale inclusion of interactive 
teaching approaches in the tertiary science classroom at the institution studied. Lecturers also reported that adequate resources were available, student participation in class activities were high and the curriculum structure made allowance for the inclusion of interactive strategies. However, time restrictions and preparation time were reported as major deterrents to the incorporation of interactive teaching strategies in the lecturers' tertiary science classrooms.

\section{References}

[1] Djajalaksana, Y. (2011). A national survey of instructional strategies used to teach informationsystems courses: An exploratory investigation. Graduate Thesis and Dissertation, University of Florida. Retrieved from http://scholarcommons.usf.edu/etd/3074

[2] Lubienski, S. T. (2000). A clash of social cultures? Students' experiences in a discussion-intensive seventh-grade mathematics classroom. The Elementary School Journal, $100,377-403$.

[3] Deslauriers, L., Schelew, E., \& Wieman, C. (2011). Improved Learning in a Large Enrollment Physics Class. Science, 332 (6031), 862-864.

[4] DfEE/QCA (Department for Education and Employment/Qualifications and Curriculum Authority). (1999). Science: The National Curriculum for England. London: DfEE.

[5] Myhill, D., \& Warren, P. (2005). Scaffolds or straitjackets? Critical moments in classroom discourse. Educational Review, $57,55-69$.

[6] Smith, L. A. (2006). Think-aloud mysteries: Using structured, sentence-by-sentence text passages to teach comprehension strategies. Reading Teacher, 59, 764-773.

[7] Tough, A. M. (1979). The Adult's Learning Projects: A Fresh Approach to Theory and Practice in Adult Learning. Toronto: Ontario Institute for Studies in Education.
[8] Meyer, C., \& Jones, T. B. (1993). Promoting active learning: Strategies for the college classroom. San Francisco: Jossey-Bass.

[9] Conway, D. (1994). Student response to hypermedia in the lecture theatre: A case study. World Conf. on Educational Hypermedia and Multimedia (ED-MEDIA '94), Vancouver, 141-146.

[10] Wilen, W. (2004). Refuting misconceptions about classroom discussion. Social Studies, 95, 33-39.

[11] Trigwell, K., Prosser, M., \& Waterhouse, F. (1999). Relations between teachers' approaches to teaching and students' approaches to learning. Higher Education, 37, 57-70.

[12] Kuh, G., Pace, R., \& Vesper, N. (1997). The development of process indicators to estimate student gains associated with good practices in undergraduate education. Research in Higher Education, 38, 435-454.

[13] Smith, P. (2000). Preparedness for flexible delivery among vocational learners. Distance Education,21, 29-48.

[14] Bland, J.M., \& Altman, D.G. (1997). Statistics notes: Cronbach's alpha. BMJ, 314, 572

[15] Weimer, M. (2011). 10 Benefits of Getting Students to Participate in Classroom Discussions. Faculty Focus. http://www.facultyfocus.com/articles/teaching-and-learning/1 0-benefits-of-getting-students-to-participate-in-classroom-disc ussions/. Accessed February 12, 2014

[16] Larson, B. E. (2000). Classroom discussion: a method of instruction and a curriculum outcome.Teaching and Teacher Educations, 16, 661-667.

[17] Steinert, Y., \& Snell, L.S. (1999). Interactive learning strategies for increasing participation in large group presentations. Medical Teacher, 21, 37-42.

[18] Gambrell, L. B. (2004). Shifts in the conversation: teacher-led, peer-led, and computer mediated discussions. The Reading Teacher, 58, 212-215.

[19] Wehrli, G., \& Nyquist, J.G. (2003). Creating an Educational Curriculum for Learners at Any Level. AABB Conference. 